\title{
Root-Knot Nematode Parasitism Suppresses Host RNA Silencing
}

\author{
E. Walsh, ${ }^{1}$ J. M. Elmore, ${ }^{2}$ and C. G. Taylor ${ }^{1}$ \\ ${ }^{1}$ Department of Plant Pathology, The Ohio State University, OARDC, Wooster, OH 44691, U.S.A.; and ${ }^{2}$ Department of Plant \\ Pathology \& Microbiology, lowa State University, Ames, IA 50011, U.S.A.
}

Accepted 7 February 2017.

\begin{abstract}
Root-knot nematodes damage crops around the world by developing complex feeding sites from normal root cells of their hosts. The ability to initiate and maintain this feeding site (composed of individual "giant cells") is essential to their parasitism process. RNA silencing pathways in plants serve a diverse set of functions, from directing growth and development to defending against invading pathogens. Influencing a host's RNA silencing pathways as a pathogenicity strategy has been well-documented for viral plant pathogens, but recently, it has become clear that silencing pathways also play an important role in other plant pathosystems. To determine if RNA silencing pathways play a role in nematode parasitism, we tested the susceptibility of plants that express a viral suppressor of RNA silencing. We observed an increase in susceptibility to nematode parasitism in plants expressing viral suppressors of RNA silencing. Results from studies utilizing a silenced reporter gene suggest that active suppression of RNA silencing pathways may be occurring during nematode parasitism. With these studies, we provide further evidence to the growing body of plant-biotic interaction research that suppression of RNA silencing is important in the successful interaction between a plant-parasitic animal and its host.
\end{abstract}

Root-knot nematodes (RKN), belonging to the genus Meloidogyne, represent one of the most economically damaging genera of plant-parasitic nematodes worldwide (Sasser 1980). RKN parasitism is dependent upon the nematode's ability to initiate and maintain its feeding site (composed of individual "giant cells") (Bird 1962). In order to manipulate the normal physiology of those host cells, RKNs secrete effector proteins that influence several pathways, including those related to cell cycle, metabolism, cell-wall modification, and defense (Hewezi and Baum 2013). RNA silencing pathways endogenous to plants have an important regulatory role in many of these pathways (Baulcombe 2004; Chen 2009; Jones-Rhoades et al. 2006; Vance and Vaucheret 2001). Influencing a host's RNA silencing pathways as a pathogenicity strategy has been well-documented for viral plant pathogens (Chellappan et al. 2004; Li et al. 1999; Ratcliff et al. 1997; Vance and Vaucheret 2001), but recently it has become clear that silencing pathways also play an important

Corresponding author: Christopher G. Taylor;

E-mail: taylor.1886@osu.edu

*The $\boldsymbol{e}$-Xtra logo stands for "electronic extra" and indicates that seven supplementary figures and one supplementary table are published online.

() 2017 The American Phytopathological Society role in other plant pathosystems (Qiao et al. 2013; Weiberg et al. 2013).

RNA silencing monitors the intracellular occurrence of double-stranded RNA (dsRNA), which can be of endogenous or exogenous origins, and processes dsRNAs into small RNAs of discrete sizes ( 21 to 25 nucleotides [nt]) termed small interfering RNAs (siRNAs). siRNAs then mediate the silencing of homologous genetic elements by guiding RNA-induced silencing complexes to complementary RNA or DNA and modulate the expression of the corresponding gene products. One of the primary functions of RNA silencing is to defend host cells against the invading nucleic acids of a virus. In fact, multiple research groups had predicted its direct involvement in antiviral defense in the 1990s (Lindbo et al. 1993; Ratcliff et al. 1997; Smith et al. 1994). Genetic data has revealed that, when certain silencing machinery components are compromised in a plant, the corresponding mutant plant becomes more susceptible to viral infection. For instance, Arabidopsis mutants such as dicerlike 2 (dcl2) and HUA enhancer 1 (henl) have been found to be hypersusceptible to various RNA viruses (Garcia-Ruiz et al. 2010; Zhang et al. 2012). In response, viruses have evolved to inhibit or evade this defense through the production of proteins that suppress these pathways. For example, potyviral helpercomponent proteinase (HC-Pro) was discovered to be a pathogenicity determinant that causes a synergistic effect during coinfections with heterologous viruses, through its ability to counteract RNA silencing (Kasschau et al. 2003; Pruss et al. 1997), interfering with both siRNA and microRNA (miRNA) pathways (Ebhardt et al. 2005; Kasschau et al. 2003). It has since been concluded that suppression of host RNA silencing, through a variety of mechanisms, is likely required for many successful viral infections (Burgyán and Havelda 2011; Vance and Vaucheret 2001).

More recently, nonviral pathogens have also been documented to produce effectors that suppress their host's silencing pathways, and the roles of posttranscriptional RNA silencing in plant pathogen-host interactions have recently been reviewed (Katiyar-Agarwal and Jin 2010; Peláez and Sanchez 2013; Weiberg et al. 2014). It has become clear that plant viruses are not alone in their production of silencing suppressors, as bacteria (Navarro et al. 2008; Wang et al. 2011) and an oomycete (Qiao et al. 2013) have also been found to utilize this virulence strategy. A well-characterized nonviral example of an effector protein that suppresses host miRNA pathways comes from a study with Pseudomonas syringae DC3000 (Navarro et al. 2008). These effectors were found to reduce mature miRNA abundances normally activated by basal defense pathways. Concurrent work with Arabidopsis mutants, deficient in RNAsilencing machinery components responsible for processing miRNAs, found them to be more susceptible to infection by 
Pseudomonas syringae, further implicating the role of miRNAs in basal defense.

The first description of a eukaryotic plant pathogen that generates silencing suppressors was Phytophthora sojae, a pathogen of soybean. Two of its effectors were shown to suppress distinct RNA silencing pathways in the host and the importance of these effects on $P$. sojae virulence was also illustrated (Qiao et al. 2013). One $P$. sojae effector induces a broad reduction in siRNA abundance, while the second affects specific transacting siRNAs (ta-siRNAs; derived from noncoding TAS genes, targeted by miRNAs). It is now anticipated that counteracting RNA silencing-mediated defense is a common strategy used by diverse pathogens to sustain their survival and reproduction.

To date, there have been indications that plant-parasitic nematodes may influence silencing pathways in their host. The abundances of both siRNAs and miRNAs in Arabidopsis, as well as some of the target genes they regulate, are altered during beet cyst nematode (BCN, Heterodera schachtii) infestation (Hewezi et al. 2008). In 2012, a miRNA was first demonstrated to play a critical role in the developmental progression of the nematode feeding site (Hewezi et al. 2012). Altered miRNA abundance has also been observed during soybean cyst nematode infestation ( $\mathrm{Li}$ et al. 2012) and within gall tissue produced by the RKN (Cabrera et al. 2016; Zhao et al. 2015). While many of these studies have examined whole infested root tissue, techniques developed to examine feeding site-specific expression of miRNAs are beginning to expand researchers' ability to investigate how plant-parasitic nematodes influence RNA silencing pathways (Díaz-Manzano et al. 2016). The objectives of this study were to determine whether hosts impaired in their RNA silencing pathways are hypersusceptible to nematode infection and whether RKN parasitism interferes with these pathways within nematode feeding sites.

\section{RESULTS}

\section{Susceptibility of plants expressing viral suppressors of RNA silencing (VSRs).}

VSRs have been found to act as important virulence factors in multiple plant pathosystems. In previous studies, VSRs have been used to determine whether silencing suppression affects a pathogen's virulence. Using a transgenic tobacco expressing the known viral suppressor P1/HC-Pro (from Tobacco etch virus [TEV], created by Mallory et al. 2001), we examined whether transgenic expression of this viral protein also rendered plants more susceptible to RKN parasitism. As shown in Figure 1A, more eggs were produced on the HC-Pro-expressing tobacco in comparison with the wild-type control. Concerned that HCPro-expressing tobacco's smaller root system and developmental delays could be confounding these results, we included the progeny of a dsRNA-silenced $\beta$-glucuronidase (GUS) $\times$ HC-Pro cross (Supplementary Fig. S1), as their phenotype is closer to that of wild-type plants. These plants, hemizygous for HC-Pro, also proved to be hypersusceptible to RKN infection (Supplementary Fig. S2). We similarly tested the susceptibility of transgenic Nicotiana benthamiana lines expressing Potato virus A (PVA) HC-Pro (Savenkov and Valkonen 2001), Turnip crinkle virus $(\mathrm{TCV})$ coat protein $(\mathrm{CP})(\mathrm{F} . \mathrm{Qu}$, personal communication), or Cymbidium ringspot virus (CRV) P19 (Lakatos et al. 2004) and also observed an increase in susceptibility in the presence of two of these VSRs (Fig. 1B); however, transgenic plants expressing P19 did not show a significant change in susceptibility. These results indicate that a host compromised in its silencing pathways is likely to be more susceptible to RKN infection.

\section{Reversal of silencing assay.}

In order to address the question of whether RKN interfere with their host's RNA silencing pathways, we adapted a method widely used by plant virologists, a reversal of silencing assay (Anandalakshmi et al. 1998). We developed a transgenic tobacco line with a single T-DNA insertion containing both the reporter enzyme GUS and a dsRNA-generating sequence corresponding to a portion of the GUS transcript (Supplementary Fig. S3A). Qiao et al. (2013) utilized a similar method to illustrate $P$. sojae effectors' interference of RNA silencing, indicated by restoration of a reporter gene's expression. The figwort mosaic virus (FMV) promoter was chosen to drive the expression of both dsRNA-GUS and full-length GUS, due to its
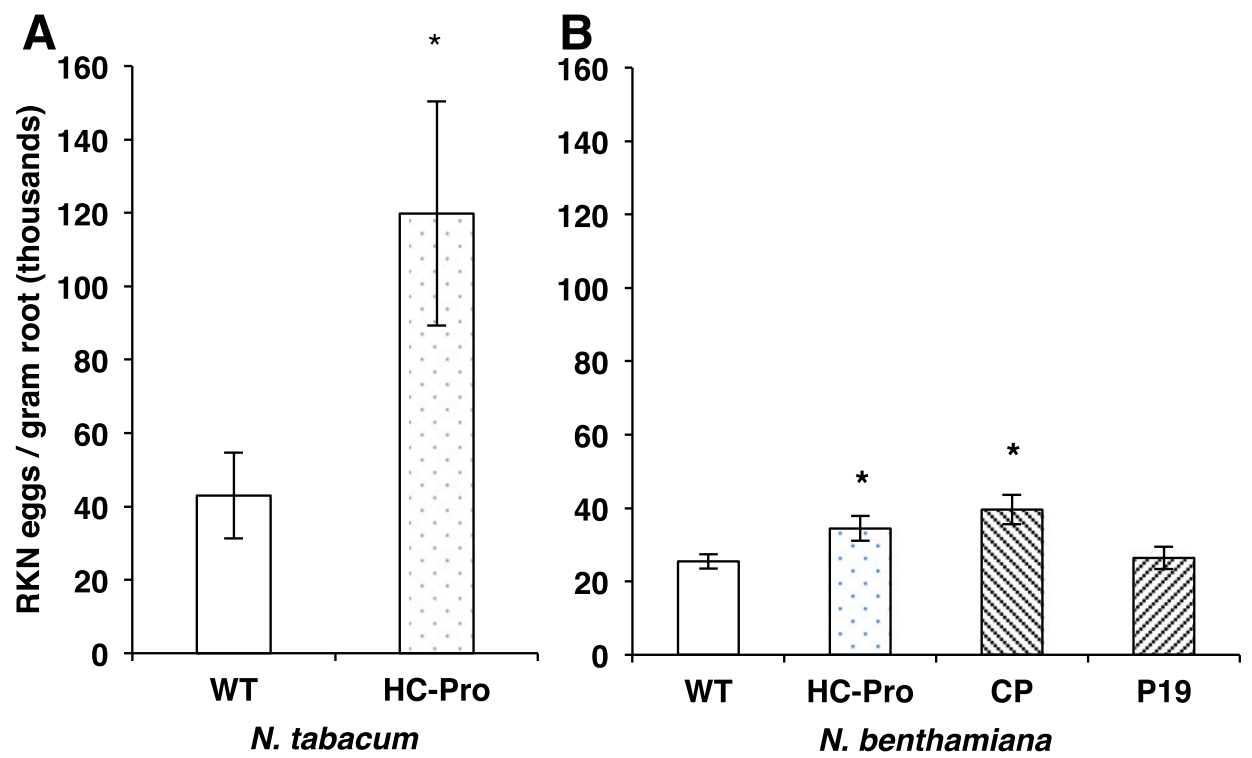

Fig. 1. A, Relative susceptibility of Tobacco etch virus helper-component proteinase (HC-Pro)-expressing tobacco to Meloidogyne incognita. Data represent the mean \pm standard error of the mean (s.e.m.), $n \geq 19$ plants; results were repeated in two additional replications (Wilcoxon, an asterisk (*) indicates $P<0.01$ ). B, Relative susceptibility of viral suppressor of RNA silencing-expressing Nicotiana benthamiana. Data represent the mean \pm s.e.m., $n \geq 24$ plants; results were repeated in two additional replications with Turnip crinkle virus coat protein $(\mathrm{CP})$ and Cymbidium ringspot virus P19 and one additional replication with Potato virus A HC-Pro (Steel's multiple comparison Wilcoxon test, an asterisk $(*)$ indicates $P<0.01$ ). 
strong expression in roots (Govindarajulu et al. 2008) and during RKN infestation (Collier et al. 2005).

The root system of the dsRNA-silenced GUS tobacco line created was void of any evident GUS expression. To verify that GUS was indeed being expressed and posttranscriptionally silenced, the line was crossed with transgenic tobacco expressing the known viral suppressor HC-Pro (Mallory et al. 2001). Several groups have utilized this strategy to illustrate HC-Pro's ability to suppress the silencing of a transgene (Anandalakshmi et al. 1998; Kasschau and Carrington 1998; Mallory et al. 2001). As expected, progeny displayed a complete recovery of GUS expression.

Tobacco plants expressing dsRNA-silenced GUS were infested with second stage juvenile (J2) RKNs and resulting root knots were stained (Supplementary Fig. S4) and were sectioned over the course of infection. From these sections, it was evident that silencing of the GUS transcript was being suppressed specifically within the nematodes' giant cells (Fig. 2 ). GUS expression was restored in the nematode feeding site as early as 4 days postinfestation (dpi) and continued for at least 21 dpi. Reverse transcription polymerase chain reaction (RTPCR) was performed on RNA collected from infested root tissue, using primers specific to the $5^{\prime}$ or $3^{\prime}$ end of the GUS gene. RT-PCR confirmed the presence of intact GUS transcript in nematode-infested tissue (Fig. 3) during nematode parasitism (data shown from $7 \mathrm{dpi}$, similar results were observed at 14 and 21 dpi [Supplementary Fig. S5]).

To ensure that the change in RNA silencing was not due to aberration or alterations using the same promoter sequences to drive GUS and the dsRNA-GUS constructs, we developed and tested tobacco lines that drove GUS expression, using a pine super ubiquitin (SU) promoter. Like the FMV-driven GUS construct, GUS expression driven by the SU promoter occurred throughout the entire root and during nematode infection (data not shown). Progeny of the cross between the dsRNA-GUS and SU-GUS transgenic tobacco lines showed no GUS expression in the root; however, when the roots were infested with RKN,
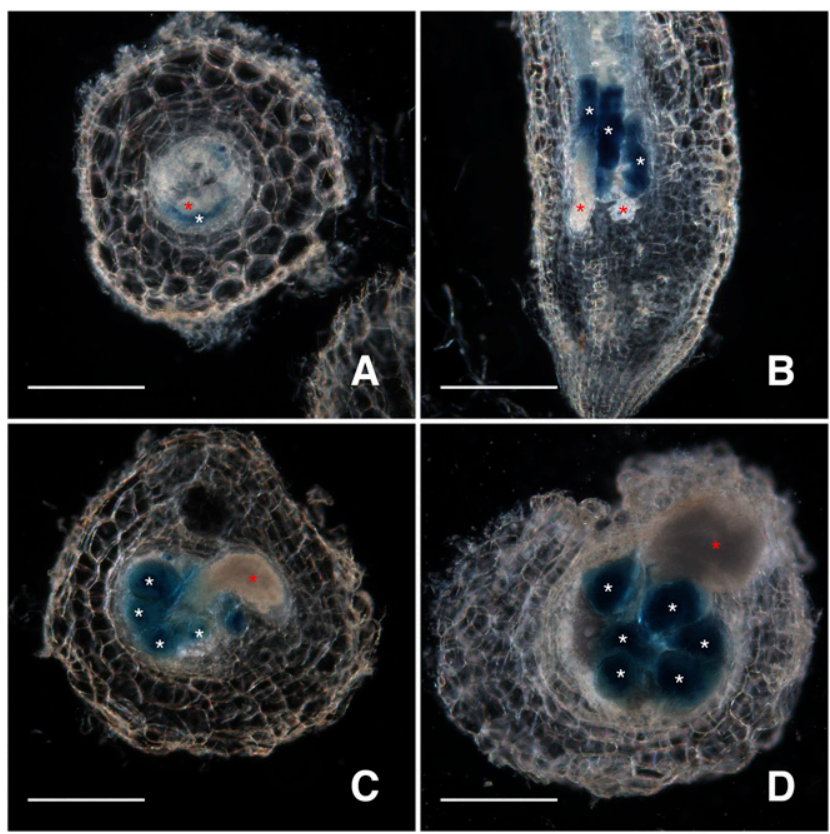

Fig. 2. Restoration of double-stranded RNA-silenced $\beta$-glucuronidase (GUS) expression in Meloidogyne incognita feeding sites. Sections were taken at A, 4, B, 7, C, 14, and D, 21 days postinfestation with second-stage juvenile worms; GUS restoration evident in nematode (red asterisks) giant cells (white asterisks) (scale bar $=100 \mu \mathrm{m}$ ).

GUS expression was restored in the nematode feeding site (Supplementary Fig. S6A).

Our previous test showed that the dsRNA-directed (siRNA) silencing pathways appear to be altered during nematode parasitism. We wanted to determine if the miRNA pathways might be altered as well. A miRNA-GUS construct was transformed into tobacco, these lines were crossed with the pSU-GUS transgenic plant, and the progeny were tested for GUS expression. In noninfested plants, GUS expression was silenced throughout the entire root system. When RKN were added, GUS expression was observed in the nematode feeding site. This suggests that mechanisms regulating both dsRNA and miRNA pathways are altered during RKN infection and that these alterations are specific to the nematode feeding site.

\section{DISCUSSION}

A diverse range of mechanisms has, so far, been characterized for VSRs (Díaz-Pendón and Ding 2008). Among the VSRs tested in this study, HC-Pro (TEV, N. tabacum, and PVA, $N$. benthamiana) and CP (TCV, $N$. benthamiana) increase host susceptibility to RKN. While HC-Pro and $\mathrm{CP}$ have both been shown to suppress silencing pathways, unlike HC-Pro, CP has been found to interfere at earlier stages (dsRNA processing) (Qi et al. 2004; Qu et al. 2003; Thomas et al. 2003). Although interfering at different points in silencing pathways, these two unrelated viruses both interact with a common host transcription factor (RAV2) (Endres et al. 2010), resulting in transcriptional changes diverted from defense. Unlike HC-Pro and $\mathrm{CP}$, we did not observe an alteration in RKN susceptibility in P19-expressing plants. Also dissimilar to the other VSRs tested, P19's primary mode of suppressing silencing is the sequestration of siRNAs (Lakatos et al. 2004). Comparing direct mechanisms of these different VSRs may help clarify why some VSRs lead to increases in susceptibility; however, the resulting effects on downstream host pathways may prove just as insightful. For example, crosstalk between small RNA pathways and jasmonate signaling has been reported (Endres et al. 2010; Zhao et al. 2015). Results from our reversal of silencing assay additionally suggest that RKN parasitism interferes with both si- and miRNAdirected silencing pathways. It is possible that RKN parasitism interferes with mechanisms or substrates common between pathways. Future work should explore the interaction with more VSRs with varying mechanisms and downstream

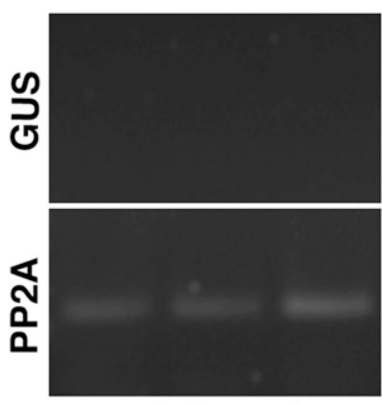

uninfected

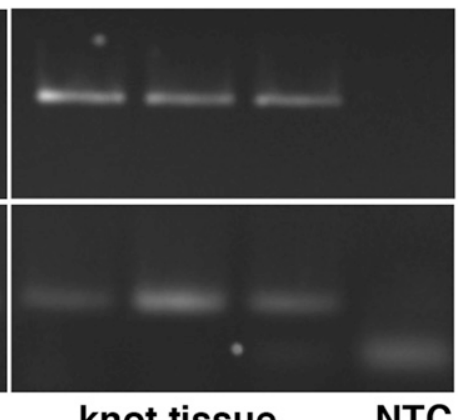

knot tissue

NTC
Fig. 3. Restoration of $\beta$-glucuronidase (GUS) transcripts in nematode feeding sites, 7 days postinfestation (dpi) with $\mathrm{J} 2$ root-knot nematodes (Meloidogyne incognita). Reverse transcription-polymerase chain reaction products produced from uninfested and infested (knot) tissue; shown are three technical replications each representing three pooled plant samples. Note the absence of GUS amplicon in uninfested tissue and the presence of GUS amplicon in knot tissue. The corresponding PP2A reference gene amplicon is presented along with no template control (NTC). Similar results were observed at 14 and $21 \mathrm{dpi}$ and tests were repeated in three independent experiments. 
effects. Additionally, examination of the nematode susceptibility of mutant plants that are missing individual components or entire RNA silencing pathways may yield further clues into the nature of suppression of RNA silencing during nematode parasitism.

Our studies using transgenic plants expressing VSRs showed an increase in nematode susceptibility. This increase in susceptibility aligns with multiple studies, done in the 1960s, showing that some virus-infected plants coinfested with RKN produce higher levels of nematode offspring than non-virus infected plants (Powell 1971). Conclusions drawn from these earlier studies focused on the basic biology of these organisms. Both nematode and viral pathogens are obligate biotrophs and, thus, sensitive to changes in their host's physiology. The results from our experiments would suggest that it is the virus-encoded VSRs that are responsible for the increase in nematode susceptibility observed in those earlier studies. Investigating nematode susceptibility of plants infected with viruses that have mutated silencing suppressors will help decipher the role of VSRs during nematode parasitism.

It is also possible that some nematodes may actually benefit from their associated viruses. In the virus-transmitting Adenophorea nematodes (Xiphinema spp., Longidorus spp., Trichodorus spp., and Paratrichodorus spp.), we speculate that the plant viruses, previously shown to be nonessential for nematode parasitism, may, in fact, alter the host plant and enhance the ability of the nematode to grow and reproduce. Future experiments could examine these relationships for any effects on nematode parasitism or feeding site productivity. Aside from diseases caused by nematode-vectored viruses, nematodeassociated viruses have been largely under-explored. The recent discoveries of viral genomes in a plant-parasitic nematode (Bekal et al. 2011, 2014) may provide additional opportunities to explore these relationships for positive effects on nematode fitness.

As evidence for further investigation, there are many studies that have examined changes in gene expression in Arabidopsis over the course of RKN and BCN infection. A tool was developed by Cabrera et al. (2014) that combines data from a few of these studies in a searchable format, NEMATIC (NEMatodeArabidopsis Transcriptomic Interaction Compendium). The expression changes in RNA silencing pathway components and target genes during RKN infection are modest but significant and do display interesting trends (Supplementary Table S1). Of the differentially expressed RNA silencing machinery genes, seven of eight are upregulated in RKN galls and 13 of 14 are upregulated in syncytia (Jammes et al. 2005; Szakasits et al. 2009). In our own microarray dataset comparing expression in giant cells versus surrounding nongiant cells (Morse et al. 2010), we observe similar trends in expression, wherein 24 of 25 RNA silencing machinery genes are upregulated. A general increase in expression of target genes is expected when RNA silencing is suppressed; however, the increase in expression of many RNA silencing machinery genes may be, in part, a consequence of the disruption of regulatory feedback loops. These latter two studies (Morse et al. 2010; Szakasits et al. 2009) observed more differentially expressed genes in these pathways than that examining gall tissue (Jammes et al. 2005), which may reflect expression changes exclusive to syncytia and giant cells. A majority of differentially expressed ta-siRNAtargeted genes are also upregulated in the syncytium and giant cell-specific studies, providing further indication that disruptions to these pathways are specific to the nematode feeding site.

Our data showing changes in nematode susceptibility in VSR plants, along with the reporter gene studies showing suppression of RNA silencing in giant cells, combined with the data gleaned from existing nematode-induced gene-expression studies indicates that there is more to be learned about how RNA interference is being suppressed during nematode parasitism. While this work illustrates that RKN parasitism suppresses host RNA silencing and that this suppression appears to be important to a successful infection, the mechanism responsible remains elusive. RKN are known to produce and secrete a plethora of proteins and small molecules during infection (Hewezi and Baum 2013; Hussey 1989), one of which could be directly interfering with silencing components much like those discovered in other pathosystems. However the RKN obligatory biotrophic lifestyle may offer other mechanisms of interference, unique to their induction of physiologically altered and maintained host cells. Further elucidation of pathway components with which RKN parasitism is interfering and how this effect is engendered will expand our understanding of the roles of RNA silencing during parasitic interactions.

\section{MATERIALS AND METHODS}

\section{Susceptibility bioassays.}

Wild-type (Nicotiana tabacum cv. Xanthi) and transgenic tobacco expressing Tobacco etch virus P1/HC-Pro (line X-27-8, created by Mallory et al. [2001]) were grown in cones with Turface sand (1:1 vol/vol) (Turface MVP; Buffalo Grove, IL, U.S.A.) amended with slow-release fertilizer. Nicotiana benthamiana lines expressing PVA HC-Pro (Lakatos et al. 2004), CRV P19 (Savenkov and Valkonen 2001), and TCV CP (F. Qu, personal communication) were treated similarly. RKN (Meloidogyne incognita) was maintained on tomato (Solanum lycopersicum cv. Moneymaker). Plants were each infested with 1,000 RKN eggs per cone. After 5 weeks, roots were cut at the crown, were rinsed with water, and fresh root weight was recorded. Roots were cut into approximately 1 -inch pieces and were submerged in 5\% bleach for 15 min with gentle agitation. Three $15-\mu \mathrm{l}$ subsamples were counted for each plant. Three independent experiments were completed with TEV HC-Pro, each including $\geq 19$ plants per line. For $N$. benthamiana $\geq 24$ plants per line were analyzed; three independent experiments were completed with TCV CP and CRV P19 and two independent experiments were completed with PVA HC-Pro.

\section{Transgenic lines.}

Tobacco plants (N. tabacum cv. Xanthi) homozygous for a single-locus T-DNA insertion line containing the GUS/dsRNAsilenced GUS (Supplementary Fig. S7A) construct were used in this experiment. The tobacco line (N. tabacum cv. Xanthi) expressing miRNA-silenced GUS was generated as the progeny of two homozygous tobacco lines, one with a single-locus T-DNA insertion expressing the miRNA and the other a singlelocus T-DNA insertion expressing GUS. The miRNA was designed using miRNA156 as a template, replacing the 22-nt binding region with sequence specific for the GUS transcript.

\section{GUS-restoration pictures.}

Root tissue was harvested (4, 7, 14, and 21 dpi with juvenile RKN, M. incognita) and was placed into $1 / 2$ strength X-Gluc (Gold Biotechnology, St. Louis) staining solution (Jefferson 1987) for $15 \mathrm{~h}$ at $37^{\circ} \mathrm{C}$. Knots were harvested and were put in a fixative solution $(3 \% \mathrm{vol} / \mathrm{vol}$ glutaraldehyde, $0.03 \%$ Triton $\mathrm{X}-100,100 \mathrm{mM}$ Tris, $\mathrm{pH} 7.0$ ) overnight at $4^{\circ} \mathrm{C}$ (Hammes et al. 2006). Knots were then placed into $3 \%$ agarose and were allowed to solidify at $4{ }^{\circ} \mathrm{C}$. Approximately $80-\mu \mathrm{m}$ sections were cut using an EMS-4000 automatic oscillating tissue slicer and were put onto slides and visualized with an inverted Leica DM IRB microscope equipped with a Q Imaging Retiga 2000 cooled digital camera. 


\section{GUS-restoration RT-PCR.}

Additional fresh tissue (RKN-infested and noninfested control) was simultaneously harvested and were immediately frozen in liquid $\mathrm{N}_{2}$. Three root samples (each from three pooled plants) were harvested for knot tissue and uninfested tissue (surrounding knots) and noninfested tissue (tissue excluding root tips) at 7, 14, and 21 dpi with J2 RKN. Total RNA was extracted with TRIZOL (Life Technologies, Carlsbad, CA, U.S.A.) and were treated with RQ1 DNase (Promega, Madison, WI, U.S.A.); measurements of quantity and quality were obtained with a Qubit 2.0 fluorometer (Life Technologies) and a Bioanalyzer (Agilent Technologies, Palo Alto, CA, U.S.A.), respectively. RNA template (500 ng) was used for cDNA synthesis, following the manufacturer's instructions, with the GoScript reverse transcription system (Promega) primed with oligo $(\mathrm{dT})_{15}$. During cDNA synthesis, a no-RT reaction was included for each RNA sample, in order to detect contaminating genomic DNA. cDNA template was diluted 1:2 and were amplified using Phusion high fidelity DNA polymerase (New England Biolabs, Ipswitch, MA, U.S.A.) with GUS-specific primers 5'-GCCAGTGGCGCGAAATATTCCCGTG (sense) and 5'-GTGCTGCGTTTCGATGCGGTCACTC (antisense), with the following cycle conditions: initial denaturation at $98^{\circ} \mathrm{C}$ for $30 \mathrm{~s}, 30$ cycles of $98^{\circ} \mathrm{C}$ for $10 \mathrm{~s}, 73^{\circ} \mathrm{C}$ for $20 \mathrm{~s}, 72^{\circ} \mathrm{C}$ for $15 \mathrm{~s}$, with a final extension at $72^{\circ} \mathrm{C}$ for $10 \mathrm{~min}$. Protein phosphatase 2A (PP2A; 123-bp region) was chosen as a gene of reference due to its relative stability shown in work with viral infections in N. benthamiana (Liu et al. 2012).

\section{Statistical analysis.}

Egg count data from susceptibility bioassays were analyzed with JMP software (version 11.0.0; SAS Institute Inc., Cary, NC, U.S.A.). Median egg counts of wild type and TEV HC-Proexpressing $N$. tabacum were compared with the nonparametric test, Wilcoxon rank sum $(P<0.01)$. Differences between means of wild type and VSR-expressing $N$. benthamiana were analyzed with the nonparametric test for multiple comparisons using Steel's multiple comparison Wilcoxon tests (comparisons of HC-Pro and $\mathrm{CP}$ with the control, $P<0.025)$.

\section{ACKNOWLEDGMENTS}

We acknowledge Z. Qi for creating the miRNA GUS construct, K. Lutke (Donald Danforth Plant Science Center, St. Louis) for creating the transgenic tobacco plants, and F. Qu for providing the Nicotiana benthamiana plants used in this study. This work was supported in part by funding from the National Science Foundation grant IOS-1104334 and The Ohio State University, Department of Plant Pathology and Center for Applied Plant Sciences, SoyRes Research Team.

\section{LITERATURE CITED}

Anandalakshmi, R., Pruss, G. J., Ge, X., Marathe, R., Mallory, A. C., Smith, T. H., and Vance, V. B. 1998. A viral suppressor of gene silencing in plants. Proc. Natl. Acad. Sci. U.S.A. 95:13079-13084.

Baulcombe, D. 2004. RNA silencing in plants. Nature 431:356-363.

Bekal, S., Domier, L. L., Gonfa, B., McCoppin, N. K., Lambert, K. N., and Bhalerao, K. 2014. A novel flavivirus in the soybean cyst nematode. J. Gen. Virol. 95:1272-1280.

Bekal, S., Domier, L. L., Niblack, T. L., and Lambert, K. N. 2011. Discovery and initial analysis of novel viral genomes in the soybean cyst nematode. J. Gen. Virol. 92:1870-1879.

Bird, A. F. 1962. The inducement of giant cells by Meloidogyne javanica. Nematologica 8:1-10.

Burgyán, J., and Havelda, Z. 2011. Viral suppressors of RNA silencing. Trends Plant Sci. 16:265-272.

Cabrera, J., Barcala, M., García, A., Rio-Machín, A., Medina, C., JaubertPossamai, S., Favery, B., Maizel, A., Ruiz-Ferrer, V., Fenoll, C., and Escobar, C. 2016. Differentially expressed small RNAs in Arabidopsis galls formed by Meloidogyne javanica: A functional role for miR390 and its TAS3-derived tasiRNAs. New Phytol. 209:1625-1640.

Cabrera, J., Bustos, R., Favery, B., Fenoll, C., and Escobar, C. 2014. NEMATIC: A simple and versatile tool for the in silico analysis of plantnematode interactions. Mol. Plant Pathol. 15:627-636.
Chellappan, P., Masona, M. V., Vanitharani, R., Taylor, N. J., and Fauquet, C. M. 2004. Broad spectrum resistance to ssDNA viruses associated with transgene-induced gene silencing in cassava. Plant Mol. Biol. 56: 601-611.

Chen, X. 2009. Small RNAs and their roles in plant development. Annu. Rev. Cell Dev. Biol. 25:21-44.

Collier, R., Fuchs, B., Walter, N., Kevin Lutke, W., and Taylor, C. G. 2005. Ex vitro composite plants: An inexpensive, rapid method for root biology. Plant J. 43:449-457.

Díaz-Manzano, F. E., Barcala, M., Engler, G., Fenoll, C., de AlmeidaEngler, J., and Escobar, C. 2016. A reliable protocol for in situ microRNAs detection in feeding sites induced by root-knot nematodes. Front. Plant Sci. 7:966.

Díaz-Pendón, J. A., and Ding, S. W. 2008. Direct and indirect roles of viral suppressors of RNA silencing in pathogenesis. Annu. Rev. Phytopathol. 46:303-326.

Ebhardt, H. A., Thi, E. P., Wang, M. B., and Unrau, P. J. 2005. Extensive 3' modification of plant small RNAs is modulated by helper componentproteinase expression. Proc. Natl. Acad. Sci. U.S.A. 102:13398-13403.

Endres, M. W., Gregory, B. D., Gao, Z., Foreman, A. W., Mlotshwa, S., Ge, X., Pruss, G. J., Ecker, J. R., Bowman, L. H., and Vance, V. 2010. Two plant viral suppressors of silencing require the ethylene-inducible host transcription factor RAV2 to block RNA silencing. PLoS Pathog. 6:e1000729.

Garcia-Ruiz, H., Takeda, A., Chapman, E. J., Sullivan, C. M., Fahlgren, N., Brempelis, K. J., and Carrington, J. C. 2010. Arabidopsis RNAdependent RNA polymerases and dicer-like proteins in antiviral defense and small interfering RNA biogenesis during Turnip mosaic virus infection. Plant Cell 22:481-496.

Govindarajulu, M., Elmore, J. M., Fester, T., and Taylor, C. G. 2008. Evaluation of constitutive viral promoters in transgenic soybean roots and nodules. Mol. Plant-Microbe Interact 21:1027-1035.

Hammes, U. Z., Nielsen, E., Honaas, L. A., Taylor, C. G., and Schachtman, D. P. 2006. AtCAT6, a sink-tissue-localized transporter for essential amino acids in Arabidopsis. Plant J. 48:414-426.

Hewezi, T., and Baum, T. J. 2013. Manipulation of plant cells by cyst and root-knot nematode effectors. Mol. Plant-Microbe Interact 26: 9-16.

Hewezi, T., Howe, P., Maier, T. R., and Baum, T. J. 2008. Arabidopsis small RNAs and their targets during cyst nematode parasitism. Mol. PlantMicrobe Interact 21:1622-1634.

Hewezi, T., Maier, T. R., Nettleton, D., and Baum, T. J. 2012. The Arabidopsis microRNA396-GRF1/GRF3 regulatory module acts as a developmental regulator in the reprogramming of root cells during cyst nematode infection. Plant Physiol. 159:321-335.

Hussey, R. S. 1989. Disease-inducing secretions of plant-parasitic nematodes. Annu. Rev. Phytopathol. 27:123-141.

Jammes, F., Lecomte, P., de Almeida-Engler, J., Bitton, F., MartinMagniette, M. L., Renou, J. P., Abad, P., and Favery, B. 2005. Genomewide expression profiling of the host response to root-knot nematode infection in Arabidopsis. Plant J. 44:447-458.

Jefferson, R. A. 1987. Assaying chimeric genes in plants: The GUS gene fusion system. Plant Mol. Biol. Report. 5:387-405.

Jones-Rhoades, M. W., Bartel, D. P., and Bartel, B. 2006. MicroRNAS and their regulatory roles in plants. Annu. Rev. Plant Biol. 57:19-53.

Kasschau, K. D., and Carrington, J. C. 1998. A counterdefensive strategy of plant viruses: Suppression of posttranscriptional gene silencing. Cell 95: 461-470.

Kasschau, K. D., Xie, Z., Allen, E., Llave, C., Chapman, E. J., Krizan, K. A., and Carrington, J. C. 2003. P1/HC-Pro, a viral suppressor of RNA silencing, interferes with Arabidopsis development and miRNA unction. Dev. Cell 4:205-217.

Katiyar-Agarwal, S., and Jin, H. 2010. Role of small RNAs in host-microbe interactions. Annu. Rev. Phytopathol. 48:225-246.

Lakatos, L., Szittya, G., Silhavy, D., and Burgyán, J. 2004. Molecular mechanism of RNA silencing suppression mediated by $\mathrm{p} 19$ protein of tombusviruses. EMBO J. 23:876-884.

Li, H. W., Lucy, A. P., Guo, H. S., Li, W. X., Ji, L. H., Wong, S. M., and Ding, S. W. 1999. Strong host resistance targeted against a viral suppressor of the plant gene silencing defence mechanism. EMBO J. 18: 2683-2691.

Li, X., Wang, X., Zhang, S., Liu, D., Duan, Y., and Dong, W. 2012. Identification of soybean microRNAs involved in soybean cyst nematode infection by deep sequencing. PLoS One 7:e39650.

Lindbo, J. A., Silva-Rosales, L., Proebsting, W. M., and Dougherty, W. G. 1993. Induction of a highly specific antiviral state in transgenic plants: Implications for regulation of gene expression and virus resistance. Plant Cell 5:1749-1759. 
Liu, D., Shi, L., Han, C., Yu, J., Li, D., and Zhang, Y. 2012. Validation of reference genes for gene expression studies in virus-infected Nicotiana benthamiana using quantitative real-time PCR. PLoS One 7:e46451.

Mallory, A., Ely, L., Smith, T. H., Marathe, R., Anandalakshmi, R., Fagard, M., Vaucheret, H., Pruss, G., Bowman, L., and Vance, V. B. 2001. HCPro suppression of transgene silencing eliminates the small RNAs but not transgene methylation or the mobile signal. Plant Cell 13: 571-583.

Morse, A. M., Carballo, V., Baldwin, D. A., Taylor, C. G., and McIntyre, L. M. 2010. Comparison between NuGEN's WT-Ovation Pico and onedirect amplification systems. J. Biomol. Tech. 21:141-147.

Navarro, L., Jay, F., Nomura, K., He, S. Y., and Voinnet, O. 2008. Suppression of the microRNA pathway by bacterial effector proteins. Science 321:964-967.

Peláez, P., and Sanchez, F. 2013. Small RNAs in plant defense responses during viral and bacterial interactions: Similarities and differences. Front. Plant Sci. 4:343.

Powell, N. T. 1971. Interaction of plant parasitic nematodes with other disease-causing agents. Pages 119-136 in: Plant Parasitic Nematodes. B. M. Zuckerman, W. F. Mai, and R. A. Rohde, eds. Academic Press, New York.

Pruss, G., Ge, X., Shi, X. M., Carrington, J.C., and Vance, V. B. 1997. Plant viral synergism: The potyviral genome encodes a broad-range pathogenicity enhancer that transactivates replication of heterologous viruses. Plant Cell 9:859-868.

Qi, Y., Zhong, X., Itaya, A., and Ding, B. 2004. Dissecting RNA silencing in protoplasts uncovers novel effects of viral suppressors on the silencing pathway at the cellular level. Nucleic Acids Res. 32:e179.

Qiao, Y., Liu, L., Xiong, Q., Flores, C., Wong, J., Shi, J., Wang, X., Liu, X., Xiang, Q., Jiang, S., Zhang, F., Wang, Y., Judelson, H. S., Chen, X., and Ma, W. 2013. Oomycete pathogens encode RNA silencing suppressors. Nat. Genet. 45:330-333.

Qu, F., Ren, T., and Morris, T. J. 2003. The coat protein of turnip crinkle virus suppresses posttranscriptional gene silencing at an early initiation step. J. Virol. 77:511-522.

Ratcliff, F., Harrison, B. D., and Baulcombe, D. C. 1997. A similarity between viral defense and gene silencing in plants. Science 276:1558-1560.
Sasser, J. N. 1980. Root-knot nematodes: A global menace to crop production. Plant Dis. 64:36-41.

Savenkov, E. I., and Valkonen, J. P. T. 2001. Potyviral helper-component proteinase expressed in transgenic plants enhances titers of Potato leaf roll virus but does not alleviate its phloem limitation. Virology 283: 285-293.

Smith, H. A., Swaney, S. L., Parks, T. D., Wernsman, E. A., and Dougherty, W. G. 1994. Transgenic plant virus resistance mediated by untranslatable sense RNAs: Expression, regulation, and fate of nonessential RNAs. Plant Cell 6:1441-1453.

Szakasits, D., Heinen, P., Wieczorek, K., Hofmann, J., Wagner, F., Kreil, D. P., Sykacek, P., Grundler, F. M. W., and Bohlmann, H. 2009. The transcriptome of syncytia induced by the cyst nematode Heterodera schachtii in Arabidopsis roots. Plant J. 57:771-784.

Thomas, C. L., Leh, V., Lederer, C., and Maule, A. J. 2003. Turnip crinkle virus coat protein mediates suppression of RNA silencing in Nicotiana benthamiana. Virology 306:33-41.

Vance, V., and Vaucheret, H. 2001. RNA silencing in plants-Defense and counterdefense. Science 292:2277-2280.

Wang, M., Soyano, T., Machida, S., Yang, J. Y., Jung, C., Chua, N. H., and Yuan, Y. A. 2011. Molecular insights into plant cell proliferation disturbance by Agrobacterium protein 6b. Genes Dev. 25:64-76.

Weiberg, A., Wang, M., Bellinger, M., and Jin, H. 2014. Small RNAs: A new paradigm in plant-microbe interactions. Annu. Rev. Phytopathol. 52:495-516.

Weiberg, A., Wang, M., Lin, F. M., Zhao, H., Zhang, Z., Kaloshian, I., Huang, H. D., and Jin, H. 2013. Fungal small RNAs suppress plant immunity by hijacking host RNA interference pathways. Science 342 : 118-123.

Zhang, X., Zhang, X., Singh, J., Li, D., and Qu, F. 2012. Temperaturedependent survival of Turnip crinkle virus-infected arabidopsis plants relies on an RNA silencing-based defense that requires dc12, AGO2, and HEN1. J. Virol. 86:6847-6854.

Zhao, W., Li, Z., Fan, J., Hu, C., Yang, R., Qi, X., Chen, H., Zhao, F., and Wang, S. 2015. Identification of jasmonic acid-associated microRNAs and characterization of the regulatory roles of the miR319/TCP4 module under root-knot nematode stress in tomato. J. Exp. Bot. 66:4653-4667. 